2018-09

\title{
Emotional Preferences and Goals and Emotion Dysregulation in Children with Asperger's Syndrome and Typically Developing Children
}

\section{Lopez-Perez, B}

http://hdl.handle.net/10026.1/10521

British Journal of Clinical Psychology

Wiley

All content in PEARL is protected by copyright law. Author manuscripts are made available in accordance with publisher policies. Please cite only the published version using the details provided on the item record or document. In the absence of an open licence (e.g. Creative Commons), permissions for further reuse of content should be sought from the publisher or author. 
Emotional Preferences and Goals and Emotion Dysregulation in Children with Asperger's Syndrome and Typically Developing Children

\author{
Belén López-Pérez \\ Department of Psychology, Liverpool Hope University, UK \\ Tamara Ambrona \\ Department of Education, Universidad Autonoma de Madrid, Spain \\ Michaela Gummerum
}

School of Psychology, Plymouth University, UK

Date accepted: 09/01/2018

Embargo release date: 09/01/2019

This is the peer-reviewed version of the following article: López-Pérez, B., Ambrona, T., \& Gummerum, M. (in press). Emotional preferences and goals and emotion dysregulation in children with Asperger's Syndrome and typically developing children. British Journal of Clinical Psychology. This article may not exactly replicate the final version published. It is not the copy of record. This work is made available online in accordance with the publisher's policies. Please refer to any applicable terms of use of the publisher. 


\begin{abstract}
Objectives: Emotion goals lie at the heart of emotion regulation, as people have to first decide what emotions they want to feel before engaging in emotion regulation. Given that children with Asperger's Syndrome (AS) are characterized by exhibiting difficulties in emotion regulation, studying whether they display similar or different emotion goals compared to typically developing children (TD) may provide insightful information.
\end{abstract}

Methods: Thirty AS and 30 TD children (10-12 years) reported about their general (i.e., how they want to feel in general) and contextualized (i.e., how they want to feel when confronting vs. collaborating with someone) emotion goals, and about their difficulties in emotion regulation through questionnaires.

Results: Results showed that both groups did not differ in their general emotional goals and in their contextualized emotion goals for happiness for collaboration and anger for confrontation. AS children only differed from TD children in a higher preference for sadness for collaboration and happiness for confrontation. These emotion goals predicted their difficulties to engage in goal-directed behaviour.

Conclusions: The obtained results support the need to further study emotion goals as an aspect of emotion dysregulation, namely the difficulties to engage in goal-directed behaviour when experiencing different emotions.

Keywords: Asperger's syndrome; children; emotion goals; emotional preferences; emotion regulation. 


\section{Practitioners Points}

- AS and TD children did not differ in their general emotion goals

- AS and TD children did not vary in their preferences for happiness for collaboration and anger for confrontation

- AS children only differed in a higher preference for sadness for collaboration and happiness for confrontation.

- Understanding emotion goals might help practitioners to develop better interventions 


\section{Emotional Goals and Emotion Dysregulation in Children with Asperger's Syndrome and Typically Developing Children}

People have different goals or cognitive representations of desired endpoints (Fishbach \& Ferguson, 2007). For instance, an individual may aim to achieve good grades, whereas another may aim to strive for being the most popular person in class. These goals represent behavioural goals, but emotions may signal whether people are achieving their (behavioural) goals or not (Baumann, Kaschel, \& Kuhl, 2005). For example, if a person does not achieve an anticipated goal, she may feel sad, and this, in turn, may become a powerful drive to accomplish the original goal (e.g., goal-performance discrepancy, Kernan \& Lord, 1990). However, emotions themselves can become desired goals or endpoints. For example, an individual may want to be happy above everything else, and therefore the experience of happiness becomes a desired goal. Indeed, emotion goals lead people to change their own and others' emotional reactions in order to attain these specific emotional states (Mauss \& Tamir, 2014).

\section{Emotion Goals and Emotion Regulation}

Emotion goals lie at the heart of emotion regulation, as people have to first decide what emotions they want to feel before initiating, inhibiting, or modifying their emotional response (Kim, Ford, Mauss, \& Tamir, 2014). Thus, without the activation of emotion goals the emotion regulation process cannot take place (Mauss, Bunge, \& Gross, 2007). The regulatory process starts when individuals perceive a discrepancy between their current emotional state (e.g., "I feel upset") and their emotion goal (e.g., "I want to feel less upset) (Mauss \& Tamir, 2014). Thus, emotion regulation is aimed at bringing the current emotional state closer to the desired emotion goal (Tamir \& Ford, 2012a). 
Although an individual may have general emotion goals (e.g., "I want to be happy"), certain situations may activate specific emotion goals to succeed in these contexts (Tamir \& Ford, 2012a). Thus, emotions become desirable if they make the attainment of a specific behavioural goal more likely (Tamir, Schwartz, Cieciuch, Riediger, Torres, et al., 2015). For example, previous research has shown how happiness can promote collaboration, how anger can benefit confrontation (Van Kleef, De Dreu, \& Manstead, 2004), or how sadness can foster analytic processing and attention to detail (Forgas, 2006). Therefore, individuals may aim to experience those emotions to successfully collaborate, confront, or process information. From this perspective, even generally "undesirable" negative emotions can be desirable if they help to achieve behavioural goals (e.g., confronting someone). In fact, recent research has shown that participants' implicit and explicit emotional preferences were different depending on the context or behavioural goal to achieve. When exposed to a behavioural confrontation goal, participants indicated not only higher preference for anger but also indicated a higher preference for anger-inducing stimuli. However, when exposed to a collaboration goal, they indicated a higher preference for happiness and a higher preference for happiness-inducing stimuli (Kim et al., 2014; Tamir \& Ford, 2012a). Thus, different behavioural goals may be linked to different emotion goals.

Given that emotion goals are at the core of the emotion regulation process, it is important to study whether emotion goals are adaptive. According to previous evidence, emotion goals should be adaptive if they are sensitive to situational demands and behavioural goals. In fact, recent research has shown that when exposed to a collaboration context the more people wanted to feel angry and the less they wanted to feel happy, the lower their wellbeing (Tamir \& Ford, 2012a). Thus, studying emotion goals in populations characterized as exhibiting emotion dysregulation may provide insightful information regarding their emotion regulation difficulties. 


\section{Emotion Regulation in Individuals with Asperger's Syndrome}

Individuals with high-functioning autism or Asperger's syndrome (AS) have been characterized as experiencing difficulties with regulating their own emotions (Mazefsky et al., 2013; Samson, Huber, \& Gross, 2012). They have been described as being more likely to use more maladaptive strategies such as avoidance (i.e., evading negative feelings and thoughts) or expressive suppression (i.e., inhibition of the expressive emotional response) (e.g., Mazefsky, Borue, Day, \& Minshew, 2014; Samson et al., 2012; Samson, Wells, Phillips, Hardan, \& Gross, 2015), which previous research has linked to increased negative affect (e.g., Aldao, Nolen-Hoekseman, \& Schweizer, 2010) and has positively related to clinical symptoms (e.g., Webb, Miles, \& Sheeran, 2012). Furthermore, individuals with AS have been characterized as less likely to use adaptive emotion regulation strategies such as problem-solving (i.e., modifying the situation to alter its emotional impact), or reappraisal (i.e., reframing a negative event in a positive way) (Jahromi, Meek, \& Ober-Reynolds, 2012; Samson et al., 2012; Samson, Hardan, Podell, Phillips, \& Gross, 2014). Although investigating emotion regulation strategies in AS individuals provides important information regarding possible emotion regulation difficulties (Aldao et al., 2010), additionally considering emotion goals can provide a broader picture about emotion dysregulation (Aldao, Sheppes, \& Gross, 2015).

Emotion goals involve emotion understanding (i.e., identifying and discriminating between different emotional experiences) as well as emotion-outcome expectancies (i.e., anticipating the outcomes linked to different emotions in distinct contexts). Previous developmental research with typically developing (TD) children has suggested that these skills develop with age, showing a significant improvement from 5 to 6 years of age (e.g., Bassett, Denham, Wyatt, \& Warren-Khot, 2012), with 10-year-olds having a similar understanding to adults. Those ten year-olds and older recognize that an individual can reflect 
on different perspectives, that different emotions may emerge from the same situation, and that the emotion displayed may not correspond to the real emotion felt by a person (see Harris, 2000, for a review). Children with AS have been described as exhibiting difficulties in emotion understanding. They struggle with understanding the influence of beliefs on emotions (Baron-Cohen, 1991), and show a significant delay in emotion understanding compared to TD children (e.g., Baron-Cohen, Wheelwright, Hill, Raste, \& Plumb, 2001). In fact, an impairment in the understanding of complex emotions (e.g., embarrassment) persists into adulthood (Baron-Cohen et al., 2001). Given these limitations, we expected children with AS to exhibit different emotional preferences when exposed to different emotion goals compared to TD children.

\section{The Present Research}

In the present study, we aimed to investigate (1) whether AS children would differ from TD children in their general (i.e., their preferred general emotions) and contextualized emotional preferences (i.e., their preferred emotions when collaborating with and confronting others) and (2) whether these differences in emotional preferences may predict emotion dysregulation. Concerning general emotion goals, previous research with adults showed that the experience of an emotional response may change people's emotion goals. For example, research with healthy-control adults showed that when they were led to experience anger they then evaluated anger as a preferred emotion (Netzer, Igra, Anan, \& Tamir, 2015). Further support for this idea was found in research with adults suffering from depression who indicated a higher preference for emotion regulation strategies that may maintain or increase their levels of sadness (Millgram, Joorman, Huppert, \& Tamir, 2015). Overall, these findings indicate that a higher experience of negative affect may lead to a higher preference for such emotional experiences. Given that children with AS tend to experience higher negative emotions and equal amounts of positive emotions than TD children (e.g., Samson et al., 
2012), we hypothesized that AS children would have a higher general preference for negative emotions than TD children and that they would not differ for positive emotions.

Regarding contextualized emotion goals, we expected differences between children with AS and TD children, as previous literature has shown they differ in emotion understanding (e.g., Baron-Cohen et al., 2001), which is a key factor in linking emotion goals to behavioural goals (Kim et al., 2014). Given that previous research with healthy-control adults has found a preference for anger to achieve a confrontation goal and a preference for happiness to achieve a collaboration goal (Tamir \& Ford, 2012b), we expected that TD children would exhibit the same pattern. However, given that children with AS are characterized by exhibiting difficulties with emotion understanding, we expected them to have a lower preference for anger for confrontation and happiness for collaboration and perceive those emotions as less useful. Given that there is no previous evidence with regards to emotion goals in AS groups, we explored whether their preference for non-matching emotion goals (i.e., sadness and anger for collaboration and happiness and sadness for confrontation) and perception of emotion utility for those emotions was different to TD children. .. Regarding emotion dysregulation, we expected AS children to rate higher in emotion dysregulation than TD children, as previous literature has identified children with AS to use more maladaptive ER strategies. Finally, we expected that scores in emotion dysregulation may be predicted not only by AS or TD status but also by those children's contextualized emotion goals, that according to previous evidence, may make less likely the achievement of a behavioural goal (i.e., happiness and sadness for confrontation and anger and sadness for collaboration) (Ford \& Tamir, 2012b; Kim et al., 2014).

Method

\section{Participants}


Thirty children with Asperger's syndrome (AS) and 30 typically developing (TD) children participated in the study in exchange of a prize equivalent to $7 €(8 \$)$. Children with AS $(M=10.97, S D=.88$, age range $10-12$ year-olds $)$ did not differ in age from TD children $(M=11.07, S D=.86$, age range $10-12$ year-olds $) ; t(58)=-.44, p=.66, d=.10$. Given that the AS sample was only comprised by males we only recruited males for the TD sample. Finally, AS children $(M=101.50, S D=11.98)$ did not differ from TD $(M=103.80, S D=.10 .71)$ children in intelligence, measured with the $5^{\text {th }}$ edition Stanford-Binet test (SB5; Roid, 2003). All participants were Caucasian and from middle socio-economic backgrounds. We selected the age range between 10-12-years, as previous research on emotion understanding with TD children has shown that from the age of 10 children understand that emotion-event links may be different depending on the person's beliefs and goals (Pons, Harris, \& de Rosnay, 2004). Therefore, this allowed testing whether TD children exhibit the same emotion goals as found previously in the research conducted with healthy-control adults. Furthermore, by restricting the age to two years we wanted to control that the obtained results could not be due to changes in maturity within each group of children. Children with AS were recruited from three different autism institutions in Spain. All participants with AS had a diagnosis of Asperger's syndrome (ICD10; F84.5), confirmed by a referring psychotherapist or psychiatrist. This diagnosis was confirmed through expert clinical evaluation based on the DSM-IV-TR (APA, 2000) and the Autism Diagnostic Interview-Revised (Lord, Rutter, \& LeCoteur, 1994) ${ }^{1}$. Furthermore, only children who did not present any psychiatric symptom (i.e., depression) were invited to participate in the study. Children with secondary autism (i.e., chromosome abnormality, single-gene disorder) or with evidence of biological disorders were excluded. This was done to ensure that the AS sample did not differ from the TD sample in

\footnotetext{
${ }^{1}$ Although children with Asperger's Syndrome may fall under the DSM-V in the category of autism, we followed the DSM-IV criteria as this was followed by the different autism associations that participated in the study since they were working under this basis since the early 2000s.
} 
terms of genetics. TD children were recruited through advertisements in areas that were comparable with the socioeconomic status of the AS participants. Potential TD participants were screened prior to participating and only those who matched children with AS in gender and age were allowed to participate. Furthermore, TD participants were screened using the Kiddie-Schedule for Affective Disorders and Schizophrenia for School-aged Children Present and Lifetime Version (K-SADS PL, Kaufman et al., 1997; Spanish version by Ulloa et al., 2006) to ensure they did not present with any psychiatric symptoms. Only one child presented with generalized anxiety and was consequently replaced with another TD child participant. Both AS and TD children were screened for cognitive functioning with the Stanford-Binet, 5th edition (SB5; Roid, 2003). Only those children with scores equal or above 80 were included in the study.

\section{Procedure}

Written informed consent was obtained from parents, and assent was obtained from all children. Participants completed different questions in order to assess their general emotional preferences and their contextualized emotional preferences. After that, participants indicated the perceived utility of each emotion for accomplishing different goals (i.e., confrontation and collaboration). Finally, participants completed the Difficulties in Emotion Regulation Scale (Gratz \& Roemer; Spanish version for children/adolescents by GómezSimón, Penelo, \& de la Osa, 2014). A research assistant assisted all participants in the completion of the questionnaires by reading not only the instructions but also the items. Participants could respond by pointing to the relevant response in the respective scales.

\section{Materials}

General Emotion Goals (Tamir \& Ford, 2012a). Children rated on 7-point Likert scale, ranging from $1=$ not at all to $7=$ extremely, to what extent they generally wanted to 
feel happiness, anger, and sadness. General happiness preference was calculated by averaging the responses to the terms happy and joyful $(\alpha=.75)$; general anger preference by averaging the terms angry and irritated $(\alpha=.73)$; and general sadness preference by averaging the terms sad and upset $(\alpha=.72)$. The terms were presented in counterbalanced order.

Contextualized Emotion Goals (Tamir \& Ford, 2012a). Children rated on a 7-point Likert scale, ranging from $1=$ not at all to $7=$ extremely, to what extent they wanted to feel happiness, sadness, and anger (in counterbalanced order) if they were collaborating with another person, trying to get an agreement with another person, confronting someone who cheated on them, and arguing with someone who betrayed them. Contextualized emotion goals were calculated by averaging participants' responses to each emotion term for the two collaboration goal scenarios and the two confrontation goal scenarios. Thus, we obtained children's preference for happiness for collaboration $(\alpha=.73)$ and confrontation $(\alpha=.70)$, preference for sadness for collaboration $(\alpha=.70)$ and confrontation $(\alpha=.75)$, and preference for anger for collaboration $(\alpha=.71)$ and confrontation $(\alpha=.72)$.

Contextualized Emotion Perception Utility (Tamir \& Ford, 2012a). Children rated on a 7-point Likert scale to what extent they thought happiness, sadness, and anger would be useful for the above two collaboration goals and the two confrontation goals. Contextualized emotions perception utility was calculated by averaging participants' responses to each emotion term for the two collaboration goal scenarios and the two confrontation goal scenarios. Thus, we obtained children's perception of utility for happiness for collaboration $(\alpha=.72)$ and confrontation $(\alpha=.71)$, perception of utility for sadness for collaboration ( $\alpha$ $=.71)$ and confrontation $(\alpha=.70)$, and perception of utility for anger for collaboration $(\alpha$ $=.75)$ and confrontation $(\alpha=.73)$. 
Difficulties in Emotion Regulation Questionnaire (Spanish version by GómezSimón et al., 2014). Children completed this 36-item questionnaire on a 5-point Likert scale ranging from $1=$ almost never to $5=$ almost always. Thus, higher scores indicate higher dysregulation. The items are grouped in six different scales: non-acceptance (i.e., nonacceptance of emotion responses; e.g. "When I'm upset, I become angry with myself for feeling that way"; $\alpha=.72$ ); awareness (i.e., lack of emotional awareness; e.g. "I pay attention to how I feel"; $\alpha=.75$ ); clarity (i.e., lack of emotional clarity; e.g. "I have difficulty making sense out of my feelings; $\alpha=.71$ ); goals (i.e., difficulties engaging in goal-directed behaviour when emotionally aroused; e.g., "When I'm upset I have difficulty focusing on other things"; $\alpha=.78$ ); impulse (i.e., impulse-control difficulties; e.g. "When I'm upset, I become out of control"; $\alpha=.71$ ); strategies (i.e., limited access to emotion regulation strategies; e.g., "When I'm upset, I know that I can find a way to eventually feel better"; $\alpha=.71$ ).

\section{Results}

\section{General Emotion Goals}

A repeated measures ANOVA with Emotion (happiness, anger, sadness) as withinsubject factor and Group (AS, TD) as between-subject factor did not show a significant interaction $\left(\mathrm{F}(2,116)=2.42, p=.09, \eta_{\mathrm{p}}^{2}=.04\right)$, only a main effect of Emotion $(\mathrm{F}(2,116)=$ $86.29, p=.001, \eta_{\mathrm{p}}^{2}=.60$ ). Overall, children had a general preference to experience happiness, over sadness $(\mathrm{d}=3.19$, S.E. $=.25, p=.001)$, and anger $(\mathrm{d}=2.76$, S.E. $=.29, p=.001)$. There was no significant effect of $\operatorname{Group}\left(\mathrm{F}(1,58)=.02, p=.90, \eta_{\mathrm{p}}^{2}=.001\right)$. Hence, AS and TD children did not differ in their general preferences for anger $(\mathrm{d}=-.47$, S.E. $=.38, p=.23)$, sadness $(\mathrm{d}=.67$, S.E. $=.49, p=.18)$, or happiness $(\mathrm{d}=-.12$, S.E. $=.19, p=.53)($ Table 1$)$.

\section{Contextualized Emotion Goals}


A repeated measures ANOVA with Goal (confrontation, collaboration) and Emotions (happiness, anger, sadness) as within-subject factors and Group as between-subject factor showed a Goal $\times$ Emotions $\times \operatorname{Group}$ interaction $\left(F(2,116)=3.64, p=.03, \eta_{p}^{2}=.06\right)$. The interactions Goal $\times \operatorname{Group}\left(F(1,116)=.04, p=.83, \eta_{\mathrm{p}}^{2}=.001\right)$ and Emotions $\times \operatorname{Group}(F(2$, $\left.116)=.28, p=.76, \eta_{p}^{2}=.005\right)$ were not significant.

Pairwise comparisons with Bonferroni corrections showed that for collaboration, AS and TD children did not differ in their preferences for anger $(\mathrm{d}=.15$, S.E. $=.15, p=.32)$ and happiness $(\mathrm{d}=.08$, S.E. $=.35, p=.81)$. However, AS children indicated a higher preference for sadness compared to TD children $(\mathrm{d}=.68$, S.E. $=.27, p=.013)$.

For confrontation, pairwise comparisons with Bonferroni corrections showed that AS and TD children did not differ in their preferences for anger $(\mathrm{d}=.33$, S.E. $=.32, p=.30)$ and sadness $(\mathrm{d}=-.27$, S.E. $=.31, p=.40)$. However, AS children indicated a higher preference for happiness compared to TD children $(\mathrm{d}=.73$, S.E. $=.31, p=.02)$.

\section{Perception of Emotion Utility}

A repeated measures ANOVA with Goal and Emotions as within-subject factors and Group as between-subject factor showed a Goal $\times$ Emotions $\times$ Group interaction $(F(2,116)$ $\left.=7.78, p=.001, \eta_{p}^{2}=.12\right)$. The interactions Goal $\times \operatorname{Group}\left(F(1,116)=.03, p=.86, \eta_{p}^{2}\right.$ $=.001)$ and Emotions $\times \operatorname{Group}\left(F(2,116)=.97, p=.38, \eta_{\mathrm{p}}^{2}=.02\right)$ were not significant.

Pairwise comparisons with Bonferroni corrections showed that for collaboration, AS children did show a higher perception of utility for anger $(\mathrm{d}=.80$, S.E. $=.28, p=.005)$ and sadness $(\mathrm{d}=.82$, S.E. $=.23, p=.001)$ compared to TD children. However, AS children indicated a lower perception of utility for happiness compared to TD children $(d=-.82$, S.E. $=.38, p=.03$ ). As it can be seen in Table 1, despite the significant difference between 
groups, AS children's responses for anger and sadness were in the range of low usefulness (i.e., values below 4 in a 7-point scale) and their response for happiness in the range of high usefulness (i.e., value above 4).

For confrontation, pairwise comparisons with Bonferroni corrections showed that AS and TD children did not differ in their perception of utility for anger $(\mathrm{d}=.15$, S.E. $=.44, p$ $=.73)$ and sadness $(\mathrm{d}=-.10$, S.E. $=.46, p=.83)$. However, AS children indicated a higher perception of utility for happiness compared to TD children $(\mathrm{d}=.90$, S.E. $=.34, p=.01)$. As it can be seen in Table 1, AS children's perception of happiness, although significantly different from TD children, was still in the continuum of low perception of utility (i.e., value below 4 in a 7-point scale).

For each group, we computed a correlation analysis between contextualized emotional goals and perception of utility. For collaboration (see Table 2), in both samples, children's ratings of preference for happiness and sadness correlated positively with their perception of utility of each target emotion, respectively. However, there was no significant correlation for preference for anger and perception of utility of that target emotion. For confrontation (see Table 3), in both samples, children's ratings of preference of each emotion target correlated with their rating of perception of utility of each corresponding emotion target.

For each behavioural goal context, we tested whether children's emotion goals were moderated by their perceived utility of emotion. We ran a series of regressions for those emotion goals where children with AS and TD children differed significantly. Thus, for collaboration, we predicted a preference for sadness, with group (-1 TD children, 1 AS children), centred perceived utility of sadness, and their interaction as simultaneous predictors. Results showed that perception of utility was a significant predictor $(\beta=.60, t=$ 
$5.17, p=.001, \mathrm{CI}[.40, .92])$. However, neither group $(\beta=.07, t=.59, p=.56$, CI $[-.17, .32])$ nor the interaction $(\beta=.01, t=.002, p=.99$, CI $[-.26, .26])$ were significant.

For confrontation, we predicted a preference for happiness, with group (-1 TD children, 1 AS children), centred perceived utility of happiness, and their interaction as simultaneous predictors. Results showed that perception of utility was a significant predictor $(\beta=.51, t=4.19, p=.001, \mathrm{CI}[.24, .67])$. However, neither group $(\beta=.13, t=1.12, p=.27$, CI $[-.13, .45])$ nor the interaction $(\beta=-.11, t=-.93, p=.36$, CI $[-.32, .12])$ were significant. Thus, regardless of whether children had AS or TD, the higher the perception of utility of a target emotion, the higher their preference for this emotion in a specific context.

\section{Difficulties in Emotion Regulation}

A repeated measures ANOVA with Emotion dysregulation (non-acceptance, impulse control, use of regulation strategies, engaging in goal-directed behaviour, lack of emotional awareness, and lack of emotion clarity) as within-subject factor and Group (AS, TD) as between-subject factor showed a main effect of $\operatorname{Group}\left(F(1,58)=10.94, p=.002, \eta_{\mathrm{p}}^{2}=.16\right)$ and an Emotion dysregulation $\times$ Group interaction $\left(F(1,58)=.86, p=.001, \eta_{\mathrm{p}}^{2}=.67\right)$. Pairwise comparisons with Bonferroni corrections showed that for AS and TD children did not differ in their scores for non-acceptance $(\mathrm{d}=-.09$, S.E. $=.17, p=.58)$, impulse control $(\mathrm{d}$ $=.29$, S.E. $=.20, p=.16)$, and use of regulation strategies $(\mathrm{d}=.08$, S.E. $=.18, p=.67)$. AS children reported more difficulties than TD children to engage in goal-directed behaviour if feeling aroused $(\mathrm{d}=-.62$, S.E. $=.21, p=.004)$, lack of emotional awareness $(\mathrm{d}=.43$, S.E. $=.17, p=.01)$, and lack of emotion clarity $(\mathrm{d}=.67$, S.E. $=.18, p=.001)$.

Given that AS and TD children differed in their ratings for difficulties to engage in goal-directed behaviour, lack of emotion clarity, and lack of emotion awareness, we tested whether these scores may be predicted by children's emotional preferences for collaboration 
and confrontation. More specifically, whether these scores may be predicted by children's preference for sadness in collaboration and happiness in confrontation, as AS and TD children only differed in these emotional preferences in such contexts. Given that the overall score for goals, clarity, and awareness were significantly correlated ( $r_{\text {clarity-goals }}=.39, p=.001$; $\left.r_{\text {clarity-awareness }}=.27, p=.03 ; r_{\text {clarity-awareness }}=.32, p=.01\right)$ we ran separate hierarchical linear regression for each of them. For each regression analysis, we entered the independent variables of group and mean-centred preferences at Step 1, and the interaction term of group and mean-centred preferences at Step 2 (see Aiken \& West, 1991). For difficulties to engage in goal-directed behaviour, there was a significant effect of group and mean-centred preference of sadness for collaboration (Figure 1a) and happiness for confrontation (Figure 1b), but there was no significant effect of the interaction (Table 4). For clarity and awareness, there was only a significant effect of group (Tables 5 and 6).

\section{Discussion}

Emotion goals have been identified as core elements in the emotion regulation process, as the emotion a person aims to feel may determine their efforts to change their current emotional response (Tamir, 2015). In the present research, we aimed to examine whether children with AS may differ from TD children in their general and contextualized emotion goals and whether these may predict emotion dysregulation. As expected, children with AS and TD children did not differ in their general preference for positive emotions (general positive emotion goals). However, contrary to expectations, children with AS did not report a higher general preference for negative emotions (general negative emotion goals) compared to TD children. Previous literature has characterized AS children as experiencing higher levels of negative affect compared to TD children (e.g., Samson et al., 2012) and experiencing higher and more intense anger and anxiety (Samson, Wells, Phillips, Hardan, \& Gross, 2014). Although previous literature has shown a link between the experience of 
negative emotions (e.g., anger) and a higher preference for those emotions (Netzer et al., 2015), in the current study we did not find that AS children showed a higher general preference for negative emotions.

Concerning contextualized emotion goals, our hypotheses were partially supported. We hypothesized but did not find that AS children indicated a lower preference for happiness in collaboration and anger in confrontation. Both AS and TD children indicated to the same extent that they preferred to experience happiness (emotion goal) if aiming to achieve collaboration (behavioural goal), and anger (emotion goal) if aiming to achieve confrontation (behavioural goal). However, AS children indicated a higher preference for sadness in collaboration and happiness in confrontation compared to TD children. Furthermore, this preference was positively related to perception of utility. The more useful they perceived sadness for collaboration and happiness for confrontation, the more participants preferred those emotions for such contexts. These obtained results may be explained by AS children's difficulties in emotion understanding and the delays and impairments they present until adulthood (Baron-Cohen et al., 2001), which may lead them to perceive other emotions as beneficial for achieving behavioural goals (e.g., happiness to confront someone who cheated) unlike healthy-controls.

Regarding emotion dysregulation, AS children indicated to have more difficulties than TD children with emotional clarity and awareness and with engaging in goal-directed behaviour, that is, difficulties focusing and achieving important tasks when experiencing negative emotions (Gratz \& Roemer, 2004). These results are in line with previous research which has shown that children with AS have more difficulties to identify and understand how they are feeling (Berthoz \& Hill, 2005; Samson et al., 2012) and to self-regulate their behaviour (Eisenberg, Spirand, \& Eggum, 2010; Jahromi, Bryce, \& Swanson, 2012; Konstantareas \& Stewart, 2006) compared to TD children. 
Finally, we examined whether children's contextualized emotion goals may predict their rating on emotion dysregulation in those scales where samples scored significantly different (i.e., difficulties to engage in goal-directed behaviour, lack of emotion clarity, and lack of emotion awareness). Our hypotheses were partially supported as we only found a significant effect of contextualized sadness preference for collaboration and happiness for confrontation as predictors for difficulties to engage in goal-directed behaviour. However, clarity and awareness were only predicted by group, such that lack of emotion clarity and awareness was positively predicted by AS status. Although we did not find that contextualized emotional preferences predicted overall emotion dysregulation, we believe that the obtained results for difficulties to engage in goal-directed behaviour are a good first step. Specifically, in the present research we assessed contextualized emotion goals, hence, desired emotions linked to behavioural goals (succeeding while collaborating vs. confronting someone); therefore, it makes sense that unexpected emotion goals (preference for sadness in collaboration and happiness in confrontation) may predict difficulties to engage in goaldirected behaviour. Although previous research showed that individuals with unexpected contextualized emotion goals rated lower in psychological well-being (Kim et al., 2014; Tamir \& Ford, 2012b), no previous research had investigated whether emotion goals may predict actual emotion dysregulation.

\section{Limitations and Future Directions}

Although our results point to the need to further study emotion goals in individuals with high-functioning autism and AS, there are some limitations which should be considered in future research. First, it is necessary to assess whether children's emotion goals are sensitive to different contexts with procedures higher in external validity. The use of experimental tasks (e.g., videogames) where children may have to achieve different goals (i.e., collaboration, confrontation, or avoidance) may provide richer information. Second, 
although we intentionally selected a specific age group to make sure that children within that age range would have similar socio-cognitive skills and results could not be explained by developmental differences, future research may benefit from including a wider age group to understand how emotion goals develop across the lifespan in AS and TD children. Third, future research would benefit from including measures of other variables which may play a significant role in children's emotion goals such as emotion understanding, counterfactual thinking, and Theory of Mind. In this vein, alexithymia, that is, difficulties to identify emotions from bodily sensations, should be considered in future research, as it has been linked to difficulties in emotion regulation in children within the autism spectrum disorder (Pandey, Sexena, \& Dubey, 2011). Furthermore, alexithymia and not emotion regulation has accounted for impaired interoception (i.e., ability to perceive one's own bodily sensations) in autism spectrum disorder (Shah, Hall, Catnur, \& Bird, 2016). Therefore, future research should take into account these variables to conduct stringent tests about the predictive value of emotion goals in emotion dysregulation in both TD and AS children. Fourth, given that previous research has shown that people's current emotional experiences play a role in the preference of different emotion goals, it is possible that the obtained results may be explained only by the present emotional experience rather than by emotion regulation. Fifth, previous research has found that social expectancies on the need to experience positive emotions can have detrimental effects on people's well-being if they do not comply with those expectancies (i.e., experience of negative instead of positive emotions) (Bastian et al., 2012; 2015). Therefore, future research should investigate whether social expectancies may also modulate AS and TD children's emotion goals and their emotion regulation. Sixth, the control group in the study was not screened for Autism, as we only relied on parents' reports; hence, there might be a (slim) possibility that some of these children could have an undetected diagnosis of Autism. Finally, in the current study we assessed emotion 
dysregulation through self-report, which may differ from what children really do to regulate their own emotions (e.g., Goldenberg, Matheson, \& Mantler, 2006). Therefore, future research should consider assessing emotion dysregulation through physiological measures by exposing and measuring children's emotional responses (e.g., changes in skin conductance) to different emotion-inducing stimuli.

\section{Conclusions}

The obtained results support the need to further study emotion goals as an aspect of emotion dysregulation, namely the difficulties to engage in goal-directed behaviour when experiencing different emotions. The obtained results suggest that there is a possible disassociation between emotion goals and regulation strategies that warrant further research especially in those clinical populations who experience difficulties in emotion regulation such as high-functioning autism and AS. Previous research showed that children with AS and high-functioning autism tended to use more maladaptive strategies than TD children (e.g., Mazefsky et al., 2013; Samson et al., 2012, 2014). However, in the present research we showed that unexpected contextualized emotion goals may play a role in children's difficulties to engage in goal-directed behaviour. Thus, emotion dysregulation in children may come not only from using a maladaptive strategy but also from holding emotion goals that may make the achievement of a behavioural goals less likely. In fact, our results have shown that in both samples (AS and TD children) a higher preference for sadness in collaboration and happiness in confrontation was linked to higher difficulties to engage in goal-directed behaviour. Although the obtained results constitute preliminary evidence of the link between emotion goals and emotion dysregulation, the combined study of both emotion goals and regulation strategies may not only expand our knowledge about emotion dysregulation in TD and AS children, but it may also help to improve current therapies for individuals with high-functioning autism or AS. In fact, current practices are either focused 
on improving children's emotion recognition and understanding (e.g., Fridenson-Hayo et al., 2017) or enhancing their use of different regulation strategies (e.g., Scarpa \& Reyes, 2011). However, our results suggest the need to connect both, as knowing what emotion one needs to feel is the first necessary step for emotion regulation to happen (Tamir, 2016). Hence, intervention programs could include some activities where children may have to reason about what emotions may be more beneficial for achieving different goals and what strategies may work best to that aim. This could also be reinforced within the family by parents/carers discussing with children about the suitability of emotions for achieving different behavioural goals. 


\section{Compliance with Ethical Standards}

This study was funded by a Santander Postgraduate Internalisation Grant awarded to the first author of this manuscript. The authors declare no conflict of interest. All procedures performed in studies involving human participants were in accordance with the ethical standards of the institutional and/or national research committee and with the 1964 Helsinki declaration and its later amendments or comparable ethical standards. Informed consent was obtained from all individual participants included in the study. 


\section{References}

Aiken, L. S. \& West, S. G. (1991). Multiple regression: Testing and interpreting interactions. Newbury Park: Sage.

Aldao, A., Nolen-Hoeksema, S. \& Schweizer, S. (2010). Emotion regulation strategies and psychopathology: A meta-analysis. Clinical Psychology Review, 30, 217-237. doi:10.1016/j.cpr.2009.11.004

Aldao, A., Sheppes, G. \& Gross, J. J. (2015). Emotion Regulation Flexibility. Cognitive Therapy and Research, 38, 263-278. doi: 10.1007/s10608-014-9662-4

American Psychiatric Association. (2000). Diagnostic and statistical manual of mental disorders (4th ed. Text rev.). Washington, DC: American Psychiatric Association.

Baron-Cohen, S. (1991). Do people with autism understand what causes emotion? Child Development, 62, 385-395. doi: 10.1111/j.1467-8624.1991.tb01539.x

Baron-Cohen, S., Wheelwright, S., Hill, J., Raste, Y., \& Plumb, I. (2001). The “'Reading the Mind in the Eyes" Test revised version: A study with normal adults, and adults with Asperger syndrome or high-functioning autism. Journal of Child Psychology and Psychiatry, 42, 241-251. doi: 10.1017/s0021963001006643

Bassett, H., Denham, S., Wyatt, T. \& Warren-Khot, H. (2012). Refining the preschool selfregulation assessment for use in preschool classrooms. Infant and Child Development, 21, 596-616. doi: 10.1002/icd.1763

Bastian, B., Koval, P., Erbas, Y., Houben, M., Pe, M., \& Kuppens, P. (2015). Sad and alone: Social expectancies for experiencing negative emotions are linked to feelings of 
loneliness. Social Psychological and Personality Science, 6, 496-503. doi: $10.1177 / 1948550614568682$

Bastian, B., Kuppens, P., Hornsey, M. J., Park, J., Koval, P., \& Uchida, Y. (2012). Feeling bad about being sad: The role of social expectancies in amplifying negative mood. Emotion, 12, 69-80. doi:10.1037/a0024755

Baumann, N., Kaschel, R., \& Kuhl, J. (2005). Striving for unwanted goals: stress-dependent discrepancies between explicit and implicit achievement motives reduce subjective well-being and increase psychosomatic symptoms. Journal of Personality and Social Psychology, 89, 781-799. doi: 10.1037/0022-3514.89.5.781

Berthoz, S. \& Hill, E.L. (2005). The validity of using self-reports to assess emotion regulation abilities in adults with autism spectrum disorder. European Psychiatry, 20, 291-298. doi.org/10.1016/j.eurpsy.2004.06.013.

Eisenberg, N., Spinrad, T. \& Eggum, N. (2010). Emotion-Related Self-Regulation and Its Relation to Children's Maladjustment. Annual Review of Clinical Psychology, 6, 495525. doi: 10.1146/annurev.clinpsy.121208.131208

Fishbach, A., \& Ferguson, M. J. (2007). The goal construct in social psychology. In E. T. Higgins \& A. W. Kruglanski (Eds.), Social psychology: Handbook of basic principles (2nd ed., pp. 490- 515). New York, NY: Guilford.

Forgas, J. P. (Ed.). (2006). Affect in social thinking and behavior. New York: Psychology Press.

Friendenson-Hayo, S., Berggren, S., Lassalle, A., Tal, S., Pigat, D., Meir-Goren, N., O’Reilly, H., Ben-Zur, S., Bolte, S., Baron-Cohen, S., \& Golan, O. (2017). 'Emotiplay’: a serious game for learning about emotions in children with autism: results of a cross-cultural 
evaluation. European Child \& Adolescent Psychiatry, 26, 979-992. doi: 10.1007/s00787-017-0968-0.

Goldenberg, I., Matheson, K. y Mantler, J. (2006). The Assessment of Emotional Intelligence: A Comparison of Performance-Based and Self-Report Methodologies. Journal of Personality Assessment, 86, 33-45. doi: 10.1207/s15327752jpa8601_05

Gómez-Simón, I., Penelo, E., \& de la Osa, N. (2014). Estructura factorial e invariancia de la Escala de Dificultades en la Regulación Emocional (DERS) en adolescentes españoles. Psicothema, 26, 401-408. doi:10.7334/psicothema2013.324

Gratz, K., \& Roemer, L. (2004). Multidimensional assessment of emotion regulation and dysregulation: Development, factor structure and initial validation of the difficulties in emotion regulation scale. Journal of Psychopathology and Behavioral Assessment, 26, 41-54. doi: 0882-2689/04/0300-0041/0

Harris, P.L. (2000). Understanding emotion. In M. Lewis \& J. Haviland-Jones (Eds.), Handbook of emotions ( $2^{\text {nd }}$ edition, pp. 281-292). New York: The Guilford Press.

Jahromi, L.B., Meek, S.E., \& Ober-Reynolds, S. (2012). Emotion regulation in the context of frustration in children with high functioning autism and their typical peers. Journal of Child Psychology and Psychiatry, 53, 1250-1258. doi: 10.1111/j.14697610.2012.02560.x.

Kaufman, J., Birmaher, B., Brent, D., Rao, U., Flynn, C., Moreci, P., et al., (1997). Schedule for Affective Disorders and Schizophrenia for School-age Children-Present and Lifetime Version (K-SADS-PL): initial reliability and validity data. Journal of the American Academy of Child and Adolescent Psychiatry, 36, 980al of doi.org/10.1097/00004583-199707000-00021 
Kernan M.C. \& Lord, R.G. (1990). The effects of valence, expectancies, and goalperformance discrepancies in single and multiple goal environments. Journal of Applied Psychology, 75, 194-203. doi: 10.1037/0021-9010.75.2.194

Kim, M., Ford, B., Mauss, I. \& Tamir, M. (2014). Knowing when to seek anger: Psychological health and context-sensitive emotional preferences. Cognition \& Emotion, 29, 1126-1136. doi: 10.1080/02699931.2014.970519

Konstantareas, M. \& Stewart, K. (2006). Affect regulation and temperament in children with autism spectrum disorder. Journal of Autism and Developmental Disorders, 36, 143154. Doi: 10.1007/s10803-005-0051-4.

Lord, C., Rutter, M., \& Le Couteur, A. (1994). Autism diagnostic interviewrevised: A revised version of a diagnostic interview for caregivers of individuals with possible pervasive developmental disorders. Journal of Autism and Developmental Disorders, 24, 659685. doi: 10.1007/bf02172145

Netzer, L. Van Kleef , G., \& Tamir, M. (2015). Interpersonal instrumental emotion regulation. Journal of Experimental Social Psychology, 58, 124-135. doi.org/10.1016/j.jesp.2015.01.006.

Mauss, I. B., Bunge, S. A. \& Gross, J.J. (2007). Automatic emotion regulation. Social and Personality Psychology Compass, 1, 146-167. doi: 10.1111/j.1751-9004.2007.00005.x

Mauss, I. B. \& Tamir, M. (2014). Emotion goals: How their content, structure, and operation shape emotion regulation. In J. J. Gross (Ed.), The handbook of emotion regulation (2nd ed., pp. 361-375). New York, NY: Guilford Press. 
Mazefsky, C.A., Borue, Z., Day, T.N., \& Minshew, N.J. (2014). Emotion regulation patterns in adolescents with high functioning autism spectrum disorder: comparison to typically developing adolescents and association with psychiatric symptoms. Autism Research, 7, 344-354. doi: 10.1002/aur.1366

Mazefsky, C.A., Herrington, J., Siegel, M., Scarpa, A., Maddox, B.B., et al. (2013). The role of emotion regulation in autism spectrum disorder. Journal of the American Academy of Child and Adolescent Psychiatry, 52, 679-688. doi:10.1016/ j.jaac.2013.05.006

Millgram, Y., Joormann, J., Huppert, J., \& Tamar, M. (2015). Sad as a Matter of Choice? Emotion- Regulation Goals in Depression. Psychological Science, June 1-13. doi: $10.1177 / 0956797615583295$

Pandey, R., Sexena, P., \& Dubey, A. (2011). Emotion regulation difficulties in alexithymia and mental health. Europe's Journal of Psychology, 7, 604-623. doi:10.5964/ejop.v7i4.155

Pons, F., Harris, P. L. \& de Rosnay, M. (2004). Emotion comprehension between 3 and 11 years: Developmental periods and hierarchical organization. European Journal of Developmental Psychology, 1, 127-152. doi: 10.1080/17405620344000022

Roid, G. H. (2003). Stanford-Binet Intelligence Scales, Fifth Edition. Itasca, IL: Riverside Publishing.

Samson, A.C., Hardan, A.Y., Podell, R.W., Phillips, J.M., \& Gross, J.J. (2015). Emotion regulation in children and adolescents with Autism Spectrum Disorder. Autism Research, 8, 9-18. doi:10.1002/aur. 1387 
Samson, A. C., Huber, O., \& Gross, J.J., (2012). Emotion regulation in Asperger's syndrome and high-functioning autism. Emotion, 12, 659-665. doi: 10.1037/a0027975

Samson, A. C., Wells, W. M., Phillips, J. M., Hardan, A. Y. \& Gross, J. J. (2014). Emotion regulation in autism spectrum disorder: Evidence from parent interviews and children's daily diaries. Journal of Child Psychology and Psychiatry, 44, 1766-1772. doi: 10.1111/jcpp.12370

Scarpa, A., \& Reyes, N. M. (2011). Improving emotion regulation with CBT in young children with high functioning autism spectrum disorders: A pilot study. Behavioral and Cognitive Psychotherapy, 39, 495-500. doi:10.1017/S1352465811000063

Shah, P., Hall, R., Catmur, C., \& Bird, G. (2016). Alexithymia, not autism, is associated with impaired interoception. Cortex, 81, 215-220. doi: 10.1016/j.cortex.2016.03.021

Tamir, M. \& Ford, B.Q. (2012a). When feeling bad is expected to be good: Emotion regulation and outcome expectancies in social conflicts. Emotion, 12, 807-816. doi:10.1037/a0024443

Tamir, M. \& Ford, B. Q. (2012b). Should people pursue feelings that feel good or feelings that do good? Emotional preferences and well-being. Emotion, 12, 1061-1070. doi:10.1037/a0027223

Tamir, M., Schwartz, S. H., Cieciuch, J., Riediger, M., Torres, C., Scollon, C., Dzokoto, V., Zhou, X., \& Vishkin, A. (2015). Desired emotions across cultures: A value-based account. Journal of Personality and Social Psychology. doi:10.1037/pspp0000072

Ulloa, R.E., Ortiz, S., Higuera, F., Nogales, I., Fresan, A., Apiquian, R., Cortes, J., Arechavaleta, B., Foulliux, C., Martinez, P., Hernandez, L., Dominguez, E., de la Peña, 
F. (2006). Inter-rater reliability of the Spanish version of the Schedule for Affective Disorders and Schizophrenia for School-Age Children-Present and Lifetime version (K-SADS-PL). Actas Españolas de Psiquiatría, 34, 36-40.

Van Kleef G., De Dreu C., \& Manstead, A. (2004). The interpersonal effects of emotions in negotiations: A motivated information processing approach. Journal of Personality and Social Psychology, 87, 510-528. doi:10.1037/0022-3514.87.4.510

Webb, T. L., Miles, E., \& Sheeran, P. (2012). Dealing with feeling: A meta-analysis of the effectiveness of strategies derived from the process model of emotion regulation. Psychological Bulletin, 138, 775-808. doi: 10.1037/a0027600 
Table 1. Means and (Standard Deviations) of Emotion Preferences and Utility by Condition and Goal Context

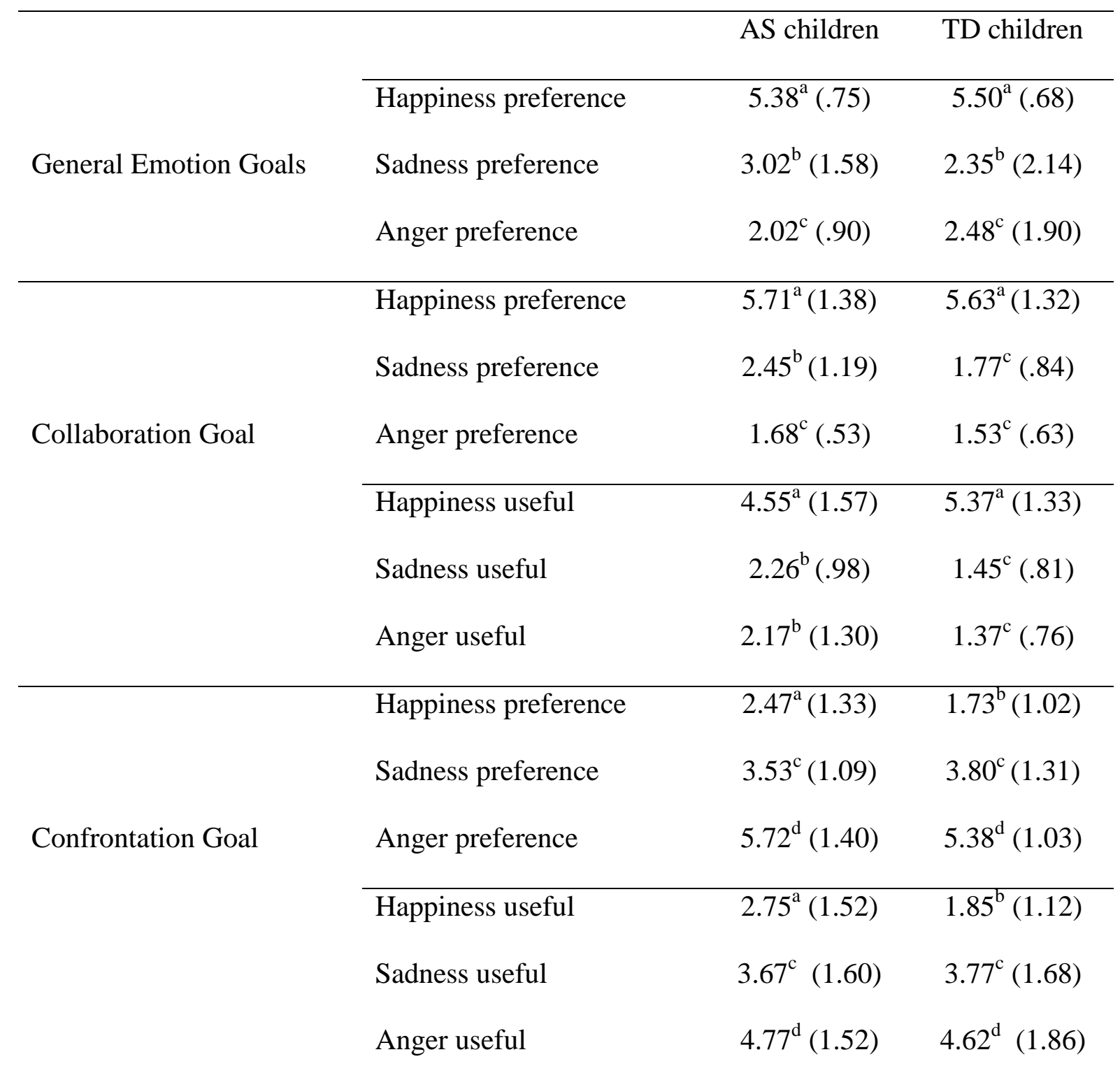

Note. Rows with different superscripts indicate statistically significant differences at $p<.01$. 
Table 2. Correlations between Emotion Preference and Perception of Emotion Utility by Context and by Group in AS children (upper triangles) and TD children (lower triangles) for Collaboration

\begin{tabular}{lcccccc}
\hline & 1 & 2 & 3 & 4 & 5 & 6 \\
\hline 1. Happiness preference & - & .32 & .13 & $.62 * *$ & .10 & .01 \\
2. Sadness preference & $-.43^{*}$ & - & .12 & .13 & $.54 * *$ & $44^{*}$ \\
3. Anger preference & -.25 & .33 & - & .17 & .33 & .20 \\
4. Happiness utility & $.63 * *$ & -.22 & -.16 & - & -.01 & $-.41^{*}$ \\
5. Sadness utility & $-.44^{*}$ & $.64 * *$ & .14 & $-.40^{*}$ & - & $.45^{*}$ \\
6. Anger utility & -.24 & $.43 *$ & .33 & -.25 & $.49 *$ & - \\
\hline
\end{tabular}

Note. $* p<.05 ; * * p<.01$. 
Table 3. Correlations between Emotion Preference and Perception of Emotion Utility by Context and by Group in AS children (upper triangles) and TD children (lower triangles) for Confrontation

\begin{tabular}{lcccccc}
\hline & 1 & 2 & 3 & 4 & 5 & 6 \\
\hline 1. Happiness preference & - & -.12 & -.08 & $.40^{*}$ & .18 & -.01 \\
2. Sadness preference & -.31 & - & -.22 & .11 & $.44^{*}$ & -.11 \\
3. Anger preference & -.21 & $.44^{*}$ & - & .17 & -.26 & $.42^{*}$ \\
4. Happiness utility & $.61^{*}$ & -.27 & -.13 & - & .25 & .03 \\
5. Sadness utility & -.22 & $.63^{* *}$ & .34 & -.34 & - & .23 \\
6. Anger utility & -.18 & .34 & $.55^{* *}$ & -.14 & $.63^{* *}$ & - \\
\hline
\end{tabular}

Note. $* p<.05 ; * * p<.01$. 
Table 4. Hierarchical Linear Regression of Difficulties with Engaging in Goal-directed

Behaviour

Difficulties with Engaging in Goal-directed Behaviour

\begin{tabular}{lllclllll}
\cline { 2 - 6 } Independent variables & $\mathrm{R}$ & $\mathrm{R}^{2}$ & $\begin{array}{c}\mathrm{R}^{2} \\
\text { change }\end{array}$ & $\mathrm{B}$ & S.E. & $\beta$ & $t$ \\
\hline
\end{tabular}

Sadness preference for

collaboration (SPC)

Step 1 $.48 \quad .23$

\begin{tabular}{|c|c|c|c|c|}
\hline Group & .22 & .10 & .26 & $2.15^{*}$ \\
\hline SPC & .26 & .09 & .33 & $2.67 * *$ \\
\hline
\end{tabular}

$\begin{array}{lllll}\text { Group } & .24 & .10 & .28 & 2.29 * \\ \text { SPC } & .21 & .10 & .27 & 2.09 * \\ \text { Group } & & & & \\ \text { x SPC } & .13 & .10 & .15 & 1.24\end{array}$

\section{Happiness preference}

for confrontation (HPC)

Step 1

$.51 \quad .26$

\begin{tabular}{lllllll} 
Group & & & .22 & .10 & .26 & $2.15^{*}$ \\
HPC & & & .25 & .08 & .36 & $3.09 * *$ \\
& & & & .26 & & \\
\hline
\end{tabular}

Step 2

$\begin{array}{lllll}\text { Group } & .22 & .10 & .26 & 2.17 * \\ \text { HPC } & .24 & .09 & .35 & 2.83 * * \\ \text { Group } & & & & \\ \mathrm{x} & .04 & .09 & .06 & .52 \\ \text { HPC } & & & & \end{array}$


Table 5. Hierarchical Linear Regression of Lack of Emotion Awareness

Lack of Emotion Awareness

\begin{tabular}{|c|c|c|c|c|c|c|c|c|}
\hline \multirow{2}{*}{\multicolumn{2}{|c|}{ Independent variables }} & \multirow{3}{*}{$\mathrm{R}$} & \multirow{3}{*}{$\mathrm{R}^{2}$} & \multirow{3}{*}{$\begin{array}{c}\mathrm{R}^{2} \\
\text { change }\end{array}$} & \multirow{3}{*}{$\mathrm{B}$} & \multirow{3}{*}{ S.E. } & \multirow{3}{*}{$\beta$} & \multirow{3}{*}{$t$} \\
\hline & & & & & & & & \\
\hline \multicolumn{2}{|l|}{ Sadness preference for } & & & & & & & \\
\hline \multicolumn{9}{|l|}{ collaboration (SPC) } \\
\hline \multirow[t]{3}{*}{ Step 1} & & .32 & .10 & & & & & \\
\hline & Group & & & & .21 & .09 & .31 & $2.32 *$ \\
\hline & SPC & & & & .02 & .08 & .04 & .28 \\
\hline \multirow[t]{5}{*}{ Step 2} & & .32 & .10 & .001 & & & & \\
\hline & Group & & & & .21 & .09 & .31 & $2.27 *$ \\
\hline & SPC & & & & .03 & .09 & .04 & .31 \\
\hline & Group x & & & & & & & \\
\hline & SPC & & & & -.01 & .09 & -.02 & -.12 \\
\hline
\end{tabular}

Happiness preference for

confrontation (HPC)

Step 1

$.32 \quad .10$

$\begin{array}{lllll}\text { Group } & .21 & .09 & .32 & 2.39 * \\ \text { HPC } & .01 & .07 & .01 & .10\end{array}$

Step 2

$\begin{array}{lll}.34 & .12 \quad .02\end{array}$

$\begin{array}{lcccc}\text { Group } & .21 & .09 & .31 & 2.31 * \\ \text { HPC } & .03 & .08 & .05 & .34 \\ \text { Group x } & & & & \\ \text { HPC } & -.07 & .08 & -.12 & -.95\end{array}$


Table 6. Hierarchical Linear Regression of Lack of Emotion Clarity

Lack of Emotion Clarity

\begin{tabular}{lllllllll}
\cline { 2 - 6 } Independent variables & $\mathrm{R}$ & $\mathrm{R}^{2}$ & $\begin{array}{c}\mathrm{R}^{2} \\
\text { change }\end{array}$ & $\mathrm{B}$ & S.E. & $\beta$ & $t$ \\
\hline
\end{tabular}

Sadness preference for

collaboration (SPC)

Step 1

$.46 \quad .21$

$\begin{array}{lllll}\text { Group } & .30 & .10 & .39 & 3.12 * * \\ \text { SPC } & .11 & .09 & .15 & 1.20\end{array}$

Step 2

$\begin{array}{lll}.46 & .21 \quad .001\end{array}$

Group

SPC

$\begin{array}{llll}.30 & .10 & .39 & 3.08 * *\end{array}$

Group x

SPC

$\begin{array}{lll}.01 & .10 \quad .01\end{array}$

.10

Happiness preference for

confrontation (HPC)

Step 1

$.44 \quad .19$

$\begin{array}{llllc}\text { Group } & .33 & .10 & .43 & 3.41 * * \\ \text { HPC } & .02 & .08 & .03 & .25\end{array}$

Step 2

$\begin{array}{lll}.44 & .19 & .001\end{array}$

Group

$.33 \quad .10$

.42

$3.35^{* *}$

HPC

$\begin{array}{lll}.03 & .08 & .04\end{array}$

.32

Group x

HPC

$\begin{array}{llll}-.03 & .08 & -.03 & -.31\end{array}$


(a)

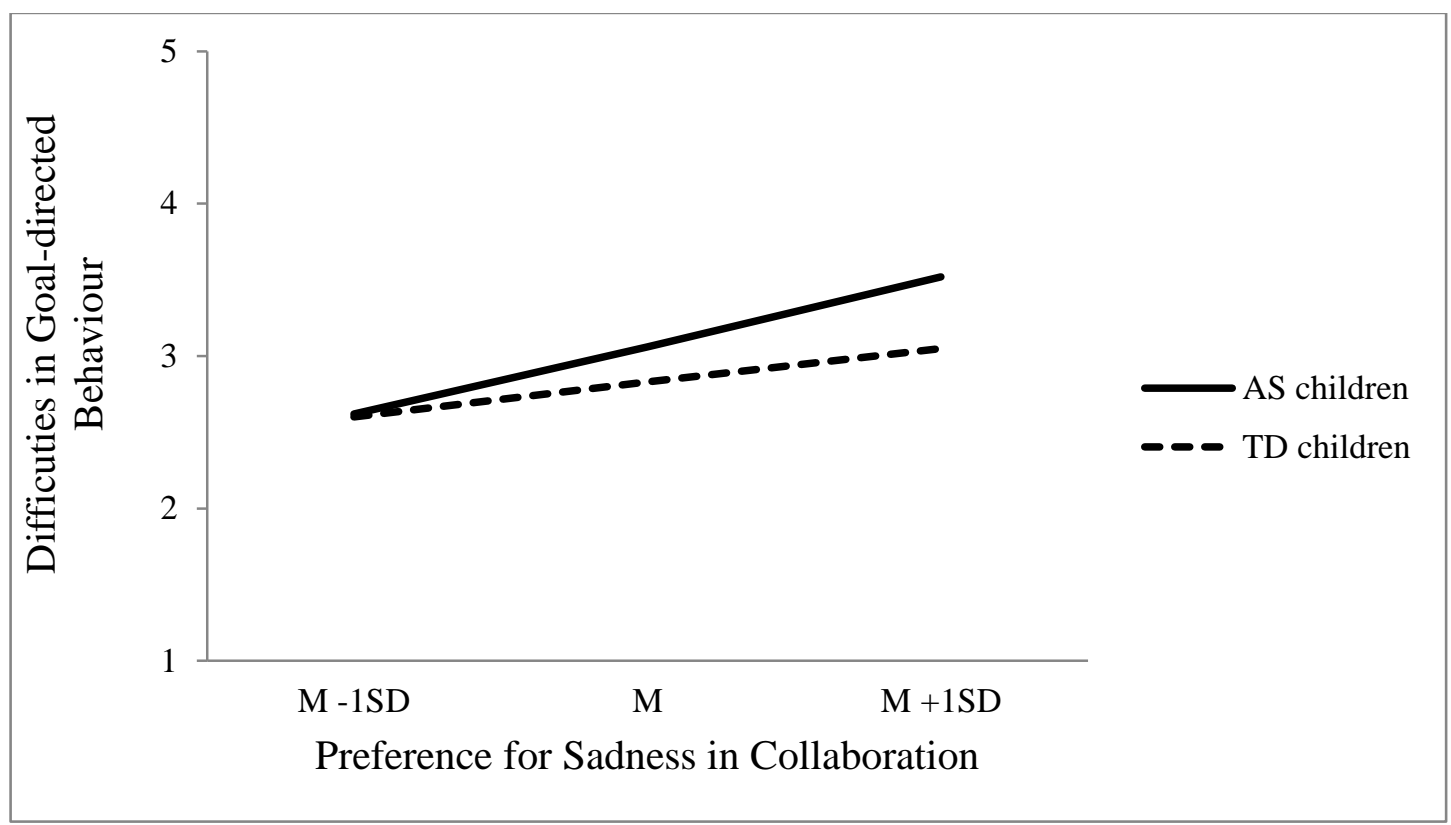

(b)

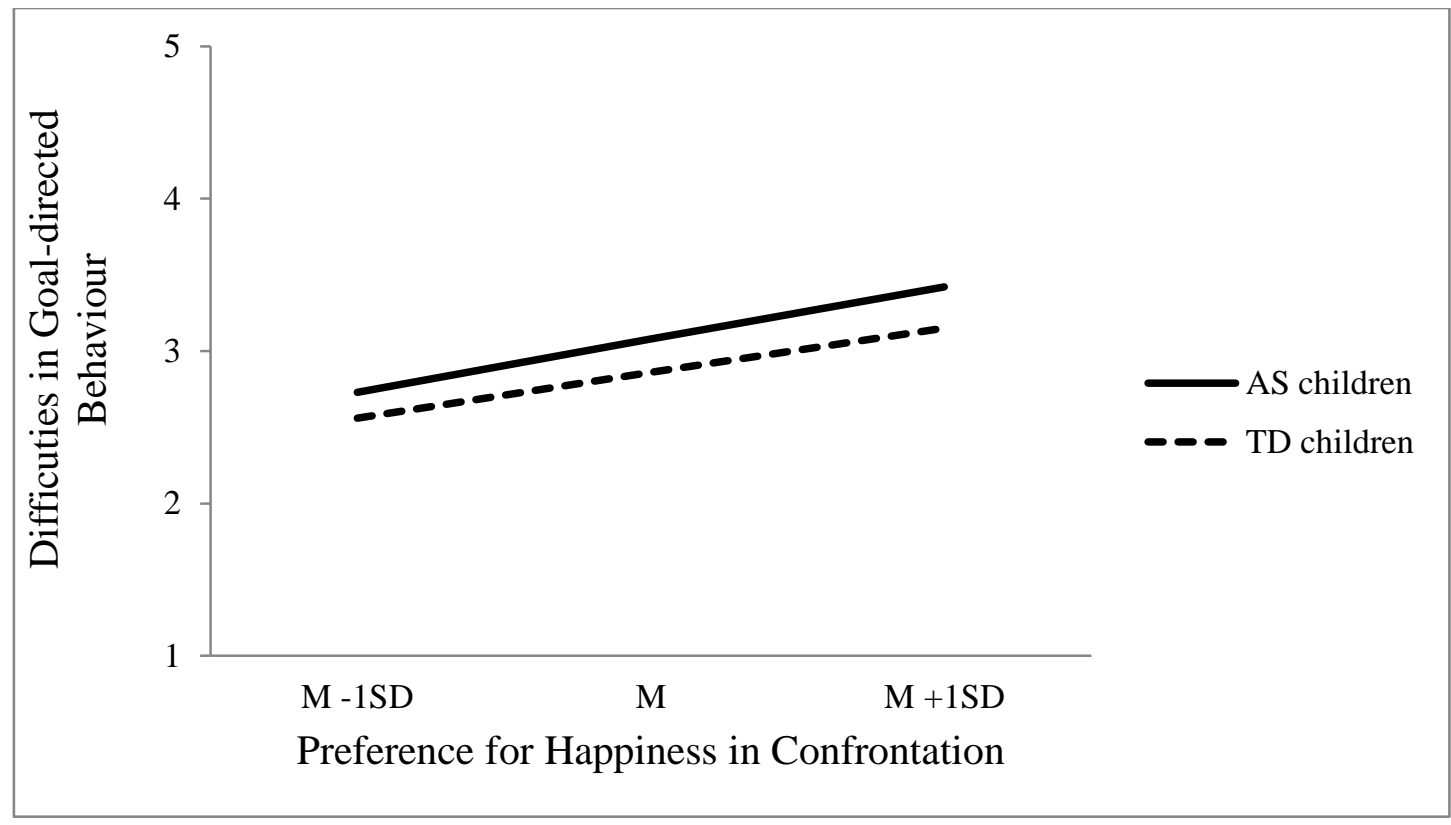

Figure 1. Test of Possible Interactions of Group with Preference for Target Emotions on the Prediction of Difficulties to Engage in Goal-directed Behaviour 